\title{
Research
}

\section{Family size, fertility preferences, and sex ratio in China in the era of the one child family policy: results from national family planning and reproductive health survey}

\author{
Qu Jian Ding, Therese Hesketh
}

\begin{abstract}
Objectives To examine the impact of the one child family policy in China on fertility, preferred family size, and sex ratio. Design Secondary analysis of data from the Chinese cross sectional national family planning and reproductive health survey, 2001. Interviews of representative sample of women aged 15-49.

Results Data were obtained from 39585 women, with a total of 73202 pregnancies and 56830 live births. The average fertility rate in women over $35(\mathrm{n}=17078)$ was $1.94(2.1 \mathrm{in}$ rural areas and 1.4 in urban areas) and for women under $35(\mathrm{n}=11543)$ 1.73 (1.25 and 1.79). Smaller families were associated with younger age, higher level of education, and living in an urban area. The male to female ratio was 1.15 and rose from 1.11 in 1980-9 to 1.23 for $1996-2001$. Most women wanted small families: $35 \%$ preferred one child and $57 \%$ preferred two. Conclusion Since the one child family policy began, the total birth rate and preferred family size have decreased, and a gross imbalance in the sex ratio has emerged.
\end{abstract}

\section{Introduction}

In 1979 the Chinese government was embarking on an ambitious programme of market reform after the economic stagnation of the cultural revolution. Strict population control was seen as essential to the success of this programme and to overall improvement in living standards, so the one child policy was introduced. The policy consists of a set of rules that govern family size; these include marrying and having children at a late age, spacing where second children are permitted, and having easy access to contraception and abortion. It is underpinned by a system of rewards and penalties, which are enforced by local officials, so interpretation of the rules varies greatly. ${ }^{1}$ The one child rule applies mainly to urban residents and government employees; in rural areas-where around $70 \%$ of the population lives-a second child is generally allowed after five years, especially if the first is a girl. ${ }^{2}$ Third children are allowed for some ethnic minorities.

The Chinese authorities have always said that the one child rule is a short term policy that aims to foster a voluntary culture of small families. ${ }^{3}$ We wanted to determine what progress has been made towards achieving this goal. We analysed data from the national family planning and reproductive health survey for 2001 to explore the fertility rate, family size preferred, and malefemale ratio. The sex ratio was included because concerns about this aspect have led to calls for a relaxation of the policy.

\begin{abstract}
Methods
The Chinese National Family Planning Commission collected data across all 31 provinces, autonomous regions, and municipalities from July to September 2001. The survey aimed to assess a nationally representative sample of women of reproductive age (15-49 years). Random sampling, using lists held by local authorities, was carried out across 346 cities and counties and 1041 villages. Interviews were carried out in the women's own homes by local health workers and covered a range of reproductive health issues. We analysed only data on issues that were relevant to this study.
\end{abstract}

\section{Results}

Data were obtained from 39585 women; 74\% were from rural areas (table A on bmj.com). The women had had a total of 73202 pregnancies and 56830 live births; 10688 (27\%) had had one or more therapeutic abortion (17\% of all pregnancies) (table 1). Smaller families (one or two children) were associated with younger age, living in urban areas, and higher level of education (table 2). In China the proportion of women who give birth after age 35 is small, so the number of children at age 35 approximates lifetime fertility. The average fertility rate in women over $35(\mathrm{n}=17078)$ was 1.94 (2.11 in rural areas and 1.43 in urban areas). Women under 35 who stated that they had completed their families $(n=11543)$ had a fertility rate of 1.73 (1.25 and 1.79), which is below replacement level.

Women who live in urban areas have no choice about family size, so we examined the association between education and family size in rural areas only $(\mathrm{n}=29512)$. Odds ratios for lower education (primary school or less) for having two or more children were 3.6 (95\% confidence interval 3.3 to 3.8 ) and for having three or more children 6.2 (5.5 to 7.0).

The sex ratio (defined as the ratio of male to female live births reported) across the whole cohort was 1.15 , with little difference between urban and rural areas (1.16 v 1.15) (table B on bmj.com). The sex ratio for first births was 1.05 in rural areas, but 1.13 in urban areas, and it rose sharply for subsequent births. To determine secular trends we analysed five year aggregates. These showed that from 1980 to 1989 the ratio was maintained at a mean of 1.11, but that it rose sharply to 1.21 in 1990-5 and was 1.23 in $1996-2001$.

Overall 57\% of women would prefer two children, and 35\% would prefer one (table 3 ). The preferred number decreased with

Additional tables $A$ and $B$ are on bmj.com 
Table 1 Outcome of 73202 pregnancies in 39 585women interviewed in the Chinese national family planning and reproductive health study, 2001. Values are number $(\%)$

\begin{tabular}{|c|c|c|c|c|c|c|c|}
\hline \multirow{2}{*}{ Pregnancy } & \multicolumn{2}{|c|}{ Live births } & \multicolumn{2}{|c|}{ Abortions } & \multirow{2}{*}{ Stillbirth } & \multirow{2}{*}{ Currently pregnant } & \multirow{2}{*}{ Total } \\
\hline & Boys & Girls & Therapeutic & Natural & & & \\
\hline $1 \mathrm{st}$ & $15106(46.8)$ & $14204(44.1)$ & 1164 (3.6) & $958(3.0)$ & $318(1.0)$ & $493(1.5)$ & 32243 \\
\hline 2nd & $9094(38.7)$ & 7354 (31.3) & $6081(25.9)$ & $602(2.6)$ & $177(0.75)$ & $215(0.9)$ & 23523 \\
\hline$\geq 4$ th & $2149(33.6)$ & $1638(25.6)$ & $2268(35.0)$ & $225(3.5)$ & $64(0.1)$ & $61(0.95)$ & 6405 \\
\hline Total & 30439 (41.6) & $26391(36.1)$ & $12770(17.4)$ & $2086(2.8)$ & $664(0.9)$ & $852(1.2)$ & 73202 \\
\hline
\end{tabular}

age and higher education and was lower among women in urban areas. Only $5.8 \%$ of women overall and $1.9 \%$ in urban areas wanted more than two children.

Over a third of the respondents (37\%) had no sex preferences. Of the $24907(63 \%)$ who did have a preference, $17882(72 \%)$ preferred a girl and a boy, whereas $2590(10 \%)$ preferred girls. Of these, $89 \%$ were women under 25 who lived in urban areas.

\section{Discussion}

This study was carried out under the auspices of the Family Planning Commission and may be prone to bias because families may conceal higher numbers of births (not approved by family planning regulations) and the local interviewers may not want to uncover violations of the rules. This is a common prob- lem with fertility surveys in China during the era of the one child policy. ${ }^{45}$ However, measures were taken to try to increase validity-for example, interviewers were instructed to ensure anonymity and confidentiality.

Both a low birth rate and the desire to have few children are prerequisites for a small family culture. The fertility rate fell from 2.9 before the policy began to 1.94 in women over 35 and 1.73 in women under $35 .{ }^{6}$ This is at the upper end of the range of estimates from different reports-the lowest is $1.5 .^{4578}$ The wide range shows how difficult it is to obtain accurate figures. Women also wanted small families: around half of the women would prefer two children and only $5.8 \%$ wanted more than two.

The normal male to female ratio at birth ranges between 1.03 and 1.07, so the ratio of 1.23 for $1995-2000$ is high. ${ }^{9}$ The high sex ratio has been well documented, ${ }^{1011}$ but these results show that the secular trends in sex ratio are greater than thought

Table 2 Family size of 39585 women interviewed in the Chinese national family planning and reproductive health study, 2001. Values are numbers (percentages) of women

\begin{tabular}{|c|c|c|c|c|c|}
\hline & \multicolumn{5}{|c|}{ No of children } \\
\hline & 0 & 1 & 2 & 3 & $\geq 4$ \\
\hline Total $(n=39585)$ & $8113(20.5)$ & $14554(36.8)$ & $11720(29.6)$ & $3887(9.8)$ & 1311 (3.3) \\
\hline \multicolumn{6}{|l|}{ Age (years): } \\
\hline $15-19(n=4470)$ & 4423 (98.9) & $48(1.1)$ & - & - & - \\
\hline $20-29(n=10322)$ & $3237(31.4)$ & $5556(53.8)$ & $1350(13.1)$ & $163(1.6)$ & $16(0.2)$ \\
\hline $30-39(n=14716)$ & $321(2.2)$ & $6312(43)$ & $6115(42.8)$ & $1577(10.7)$ & $391(2.7)$ \\
\hline $40-49(n=10074)$ & $132(1.3)$ & $2638(26.2)$ & $4255(42.2)$ & $2147(21.3)$ & $904(9.0)$ \\
\hline \multicolumn{6}{|l|}{ Area of residence: } \\
\hline Urban $(n=10072)$ & $2491(24.7)$ & 5996 (59.5) & $1285(12.8)$ & $233(2.3)$ & $67(0.7)$ \\
\hline Rural (n=29 513) & $5622(19.0)$ & $8558(29.0)$ & $10435(35.4)$ & 3654 (12.4) & $1244(4.2)$ \\
\hline \multicolumn{6}{|l|}{ Education: } \\
\hline Illiterate or semi-literate $(n=6590)$ & $315(4.8)$ & $1121(17.0)$ & $2954(44.8)$ & $1572(23.9)$ & $628(9.5)$ \\
\hline Primary school $(n=11326)$ & $1266(11.2)$ & $3534(31.2)$ & $4632(40.9)$ & 1415 (12.5) & $481(4.2)$ \\
\hline Secondary school (19 749) & $5804(29.4)$ & $8770(44.4)$ & $4079(20.7)$ & $894(4.5)$ & $202(10.2)$ \\
\hline College or university $(n=1918)$ & 728 (37.9) & $1129(58.9)$ & $55(2.9)$ & $6(0.3)$ & - \\
\hline
\end{tabular}

Table 3 Preferred family size in 39344 women interviewed in the Chinese national family planning and reproductive health study, 2001. Values are percentages unless indicated otherwise

\begin{tabular}{|c|c|c|c|c|c|}
\hline \multirow{2}{*}{ Characteristics of mother } & \multicolumn{4}{|c|}{ No of children preferred } & \multirow{2}{*}{ Mean } \\
\hline & 0 & 1 & 2 & $\geq 3$ & \\
\hline \multicolumn{6}{|l|}{ Age (years): } \\
\hline $15-19$ & 2.1 & 49 & 45 & 1.9 & 1.45 \\
\hline $30-39$ & 0.8 & 32 & 60 & 6.1 & 1.76 \\
\hline $40-49$ & 1.0 & 27 & 62 & 11 & 1.83 \\
\hline \multicolumn{6}{|l|}{ Area of residence: } \\
\hline Rural & 0.4 & 30 & 61 & 7.5 & 1.77 \\
\hline \multicolumn{6}{|l|}{ Education: } \\
\hline Illiterate or semi-literate & 0.4 & 17 & 67 & 14 & 1.98 \\
\hline Primary school & 0.3 & 25 & 65 & 8.5 & 1.84 \\
\hline Secondary school & 2.1 & 46 & 47 & 2.5 & 1.50 \\
\hline College & 4.0 & 49 & 44 & 2.2 & 1.43 \\
\hline Overall & 1.1 & 35 & 57 & 5.8 & 1.71 \\
\hline
\end{tabular}


previously; this was true for both urban and rural China, not just rural areas. ${ }^{12}$ It seems that in urban areas-where only one child is allowed-some people select the sex of their child at first birth. In rural areas most people are permitted a second child, especially if the first is a girl, so sex selection starts with the second pregnancy. This probably occurs mainly through sex selective abortion, although figures are impossible to obtain because this practice is illegal. Other reasons for fewer girls are female infanticide (although this is probably very rare now), less aggressive management of newborn girls who are sick, ${ }^{13}$ and non-registration of girls. ${ }^{14}$

It is not clear how much these demographic changes are due to the one child policy. Many countries are seeing decreases in fertility rates, and neighbouring east Asian countries have some of the lowest total fertility rates in the world: 1.38 for Japan, 1.04 for Singapore, and 0.91 for Hong Kong. ${ }^{15}$ Thus the fertility rate may have continued to fall from the 2.9 seen in 1979 even without the one child policy. Likewise many other Asian countries that have declining birth rates and traditional preferences for male babies are seeing serious sex imbalances: 1.19 for Taiwan, 1.18 for Singapore, 1.12 for South Korea, and 1.20 for parts of northern India. ${ }^{16}$ Even without the policy, sex selective abortion would be likely to continue, although it would probably be less common. This can only be solved by a change in attitudes towards female offspring. Our finding that many younger women in urban areas now express a preference for girls provides evidence that attitudes may be changing.

Since the start of the one child family policy, the total birth rate and the preferred family size have decreased, but a gross imbalance in the sex ratio has also emerged. These findings have clear implications for decisions about future population policy. A relaxation in the policy could be considered in the near future. Recommendations that all couples should be allowed to have two children, but not more than two, have already been made. ${ }^{3}{ }^{17}$ It is unlikely that a baby boom would result, and such a change in policy might help to correct the abnormal sex ratio.

Contributors: QJD was part of the team that designed the study and assisted in data collection in Zhejiang Province. QJD and TH analysed the data and $\mathrm{TH}$ wrote the paper. QJD and $\mathrm{TH}$ are guarantors.

Funding: None

Competing interests: None declared.

Ethical approval: National Family Planning Commission standards committee.

1 Zhu WX. The one child family policy. Arch Dis Child 2003;88:463-4.
2 Li J. Gender inequality, family planning and maternal and child care in a rural Chinese county. Soc Sci Med 2004;59:659-708.

3 Greenhalgh S, Bongaarts J. Fertility policy in China: future options. Science 1987:235:1167-72.

4 Merli MG, Raftery AE. Are births underreported in rural China? Manipulation of statistical records in response to China's population policies. Demography 2000;37:109-26.

5 Goodkind DM. China's missing children: the 2000 census underreporting surprise. Popul Studies 2004;58:281-5.

6 Yao XW, Yin H. Basic data of China's population. Beijing: China Population Publishing House, 1994.

7 Retherford RD, Choe MK, Chen J, Li X, Cui H. How far has infertility in China really declined? Popul Dev Rev 2005:31:57-84.

8 Winkler EA. Chinese reproductive policy at the turn of the millennium: dynamic stability. Popul Dev Rev 2002;28:379-418.

9 Davis DL, Gottlieb MB, Stampnitsky JR. Reduced ratio of male to female births in several industrial countries. JAMA 1998;279:1018-23.

10 Sen A. Missing women-revisited. BMJ 2003;327:1297-8.

$11 \mathrm{Gu}$ B, Roy K. Sex ratio at birth in China, with reference to other areas in East Asia; what we know. Asia Pac Popul J 1995;10:17-42.

12 Coale A, Banister J. Five decades of missing girls in China. Demography 1994;31:459-79.

13 Peabody JW, Hesketh T, Kattwinkel J. Creation of a neonatology facility in developing country: experience from a 5-year project in China. Am J Perinatol 1992;9:401-8.

14 Bogg L. Family planning in China: out of control? Am J Public Health 1998;88:649-51.

15 United Nations Development Program (UNDP). Human development indicators in world development report 2003. http://hdr.undp/org/reports/global/2003 (accessed 1 Sep 2005).

16 World Bank Health Nutrition and Population Division. Development data 2004. www.worldbank.org/hnpstats (accessed 1 Sep 2005).

17 Hesketh T, Li L, Zhu WX. The effect of China's one-child family policy after 25 years. $N$ Engl J Med 353:1171-6.

(Accepted 8 November 2005)

doi $10.1136 /$ bmj.38775.672662.80

Institute of Population Studies, Zhejiang University, Hangzhou 310012, PR China Qu Jian Ding associate professor

Centre for International Child Health, Institute of Child Health, London WC1 N1EH

Therese Hesketh senior lecturer

Correspondence to: T Hesketh t.hesketh@ich.ucl.ac.uk

\section{What is already known on this topic}

The one child family policy has been in force in China since 1979 and was intended as a short term measure

\section{What this study adds}

The total birth rate has dropped from 2.9 before the policy to 1.94 in women over 35 and 1.73 in women under 35

The male to female ratio has increased since the policy began, from 1.11 in 1980-9 to 1.23 for 1996-2001, and it is an urban and rural phenomenon

Most women want small families: 35\% would prefer one child, $57 \%$ two, and only $5.8 \%$ more than two 